\title{
Smart Health Monitoring System
}

\author{
Shruthi Nair \\ Department of Computer Engineering \\ FCRIT, Vashi \\ Navi Mumbai, India
}

\author{
Leo Varghese \\ Department of Computer Engineering \\ FCRIT, Vashi \\ Navi Mumbai, India
}

\author{
Nimmy Augustine \\ Department of Computer Engineering \\ FCRIT, Vashi \\ Navi Mumbai, India
}

\begin{abstract}
Monitoring and keeping track of the health status of a patient at home is a difficult task. Especially old age patients should be periodically monitored and their health status needs to be informed to the concerned doctor from time to time so that an immediate required action can be taken. Our aim is to address these challenges. In this paper, we propose a system that puts forward a smart health monitoring system that uses sensors to track patient's health and uses internet to inform their respective doctor or family members in case of any emergency issues. The system is developed for patients who are not in critical condition but need to be periodically monitored by the doctor or any family member. Our system uses temperature as well as heartbeat sensor to keep track of patient health. It mainly focuses on the situation where the doctors and patients are at distant location and it is very important to give the entire details about the patient to the doctor. If the system detects any abrupt changes such as body temperature rises above the given limit or abnormality in the heartbeat, the system automatically alerts the doctor about the patient's status over IOT device. As per tracked by the smart patient health monitoring system, the doctor can take the required action. The information that has been sent to the doctor can be made secure without any interference of the third party through Blockchain technology by making use of smart contract.
\end{abstract}

\section{Keywords-Health Monitoring, Sensors, IOT, Blockchain}

\section{INTRODUCTION}

In traditional methods, the health of a human body is monitored using thermometer, oximeter, etc. A thermometer used to take the body temperature. When some activities are carried out, small changes in body temperature will be detected [5]. Pulse oximeters are devices that measure oxygen level in human body. The device may be attached to a finger, a wrist, a foot, or any other area where the device can read blood flow [6]. A heart rate monitor (HRM) is a personal monitoring device that allows one to measure/display heart rate in realtime [7]. Fitbit tracks every part of your day, including activity, exercise, food, weight and sleep, pulse rate and steps [8]. Doctors play an important role in health checkup. The process requires a lot of time for registration, appointment and then checkup. Due to this lengthy process working people tend to ignore the checkups. Doctors play an important role in health checkup. The process requires a lot of time for registration, appointment and then checkup. Due to this lengthy process working people tend to ignore the checkups. Present-day systems use health monitoring devices which are connected to the patients at the hospital. The use of these machines detects the conditions of the patient and the data is collected and transferred to the connected monitoring systems. Doctors and staff need to visit the patient frequently to examine his/her condition. The smart health monitoring system can provide information required to monitor the health parameters of the patient. Wireless sensors are used to collect and transmit the data and to display the data on the web page. This system can be useful for the following people:-

1. A patient who has undergone certain treatment and due to which it is required to monitor certain health parameters.

2. A patient who has suffered from a heart attack before and to prevent it to occur in the future, the required health parameters can be monitored remotely. 3. A patient who is paralytic can use the system to monitor the required health parameters as advised by the doctor.

4. Athletics during the training period can check their current health parameters.

5. The people at an advanced age and maybe having failing health conditions can use this system to monitor the current health conditions.

\section{LITERATURE REVIEW}

Internet of Things (IoT)-enabled devices have created remote monitoring in the healthcare sector potential. It has reduced the costs and improved the health treatment of patients. IOT helps in collecting the information from various sensors and analyzing the data in real time. Connecting these devices to the patient's body will allow easy monitoring by the staff and can save lives in any emergencies. Users can access the data resulting in better analysis of the patient. Different papers used different applications and methods in IoT healthcare system. The works are shown in the following as

\section{A. Wireless Health Monitoring System For Patients}

The project was to observe patients without having to be physically present at their bedside, be it in the hospital or in their home. A patient's body temperature, heart rate and electrocardiography (ECG) are transferred wirelessly through Bluetooth technology. The temperature sensor chosen was LM35 IC. The ECG had three electrodes that can monitor 
heart from three different angles. The heart rate monitoring was a follow up to the system for obtaining the electrocardiograph. After obtaining the electrocardiograph, the Arduino Uno was programmed to obtain the heart beat rate of that particular reading. The purpose of the Arduino was to show the result in the local PC and the Bluetooth is to transfer the same data wirelessly to the server $\mathrm{PC}$ or smartphone. Xoscillo software helped to observe the waveshape of the ECG. The project was to overcome the difficulty that is encountered by experts in monitoring multiple patients at a time [1]

\section{B. Smart health monitoring system of patient through IoT}

The general design of IoT applications can be partitioned into three layers: the detecting layer, the transport layer and the application layer. In the Detecting layer, to measure the body temperature DS18B20 body water resist body temperature sensor is used. To measure the heart beat rate of the patient, pulse sensor amped are used. To recognize the Electrocardiogram, AD8232 Heart-Rate observing sensor are used. The Bio data from the sensors is checked in Arduino using the serial monitor. In the Transport layer the information is sent to the cloud by utilizing the Arduino with the assistance of an Ethernet shield or Wi-Fi Module ESP8266. Here the system utilize an open cloud server i.e. "Thingspeak" to make it accessible in cloud. Through ThingsSpeak an API key is generated. This API key is utilized while programming in Arduino with the end goal that the information is put in the server through the API key and at the application layer the information can be recovered by the utilization of an API key. The information of the patient including the location and the health parameters can be viewed in a graphical format with the help of Thingspeak [2].

\section{Internet of things (IoT) based smart health care system}

For monitoring health parameters like temperature, pulse rate and blood pressure respectively, three sensors are connected to the Arduino Fio transmitter board. The xbee module is connected to the board. The sensed values are wirelessly transmitted to the arduino receiver which is connected to the patient side computer and the values are read in labVIEW which is connected to the Internet. A URL is generated by labVIEW which can be accessed from any computer .In this paper, tele-monitoring application is presented which allows the doctor to view the patient's vital parameters remotely and dynamically in a Web page in real time and doesn't need to have any special requirement on the PC; through an Internet access. For the patient side, a home based LabVIEW application which is embedded in home PC is required [3].

\section{Patient Health Monitoring System Based on Internet Of Things}

In this paper, a circuit was developed which can sense the temperature and heart-beat of the human body, and if it exceeds a certain set limit, then an alarm would be raised over IOT Gecko platform on the Internet. LM35 sensor was used to read temperature values whereas heartbeat sensor module gave heart rate of patient which was sent to microcontroller unit which thereby use to send this data to LCD for display as well as to ESP8266 WiFi protocol to display the measured readings over IOT Gecko Internet
Platform. During an emergency, an alarm would be raised over the internet platform notifying the doctor about critical status of patient over internet. The doctors were able to monitor the health-related data of patient using the unique IP $\&$ login id over the IOT gecko platform over which the instantaneous health related data of the patient used to be updated [4].

\begin{tabular}{|c|c|c|c|c|}
\hline Name & Location & Description & Disadvantages & Publication \\
\hline $\begin{array}{l}\text { Wireless } \\
\text { Health } \\
\text { Monitoring } \\
\text { System } \\
\text { For } \\
\text { Patients }\end{array}$ & $\begin{array}{l}\text { American } \\
\text { International } \\
\text { University- } \\
\text { Bangladesh, } \\
\text { Dhaka, } \\
\text { Bangladesh }\end{array}$ & $\begin{array}{l}\text { Health Monitoring } \\
\text { System using } \\
\text { sensors and } \\
\text { Bluetooth } \\
\text { technology }\end{array}$ & $\begin{array}{l}\text { The system is } \\
\text { not storing real } \\
\text { time medical } \\
\text { data safely and } \\
\text { securely }\end{array}$ & $\begin{array}{l}2015 \text { IEEE } \\
\text { International } \\
\text { WIE } \\
\text { Conference } \\
\text { on Electrical } \\
\text { and } \\
\text { Computer } \\
\text { Engineering }\end{array}$ \\
\hline $\begin{array}{l}\text { Patient } \\
\text { Health } \\
\text { Monitoring } \\
\text { System } \\
\text { Based on } \\
\text { Internet Of } \\
\text { Things }\end{array}$ & $\begin{array}{l}\text { Birla Institute } \\
\text { of Technology } \\
\& \text { Science } \\
\text { (BITS), Pilani, } \\
\text { Rajasthan }\end{array}$ & $\begin{array}{l}\text { A circuit which } \\
\text { can sense the } \\
\text { temperature and } \\
\text { heart-beat of the } \\
\text { human body, and } \\
\text { if it exceeds a } \\
\text { certain set limit, } \\
\text { then an alarm } \\
\text { would be raised } \\
\text { over IOT Gecko } \\
\text { platform on } \\
\text { internet }\end{array}$ & $\begin{array}{l}\text { Use of only } \\
\text { two sensors- } \\
\text { temperature } \\
\text { and heart rate } \\
\text { Security }\end{array}$ & $\begin{array}{l}2017 \text { Fourth } \\
\text { International } \\
\text { Conference } \\
\text { on Image } \\
\text { Information } \\
\text { Processing } \\
\text { (ICIIP) }\end{array}$ \\
\hline $\begin{array}{l}\text { Smart } \\
\text { Health } \\
\text { Monitoring } \\
\text { System } \\
\text { Of patient } \\
\text { Through } \\
\text { Iot }\end{array}$ & $\begin{array}{l}\text { Potti } \\
\text { Sriramulu } \\
\text { Chalavadi } \\
\text { Mallikarjunaro } \\
\text { College of } \\
\text { Engineering } \\
\text { and } \\
\text { Technology, } \\
\text { Vijayawada, } \\
\text { India. }\end{array}$ & $\begin{array}{l}\text { Smart health } \\
\text { Monitoring } \\
\text { System monitoring } \\
\text { health parameters } \\
\text { like blood } \\
\text { pressure, } \\
\text { temperature, ECG } \\
\text { by using } \\
\text { Thingspeak } \\
\text { software. }\end{array}$ & $\begin{array}{l}\text { The system } \\
\text { does not } \\
\text { provide any } \\
\text { security } \\
\text { features. }\end{array}$ & $\begin{array}{l}\text { International } \\
\text { conference } \\
\text { on I-SMAC } \\
\text { (IoT in } \\
\text { Social, } \\
\text { Mobile, } \\
\text { Analytics } \\
\text { and Cloud) } \\
\text { (I-SMAC } \\
\text { 2017) }\end{array}$ \\
\hline $\begin{array}{l}\text { Internet of } \\
\text { things } \\
\text { (IoT) } \\
\text { based } \\
\text { smart } \\
\text { health care } \\
\text { system }\end{array}$ & $\begin{array}{l}\text { GNITS, } \\
\text { Hyderabad, } \\
\text { India }\end{array}$ & $\begin{array}{l}\text { A system that } \\
\text { allows the doctor } \\
\text { to view the } \\
\text { patient's vital } \\
\text { parameters } \\
\text { Remotely and } \\
\text { dynamically in a } \\
\text { Web page in real } \\
\text { time through an } \\
\text { Internet access. } \\
\text { For the patient } \\
\text { side, a home based } \\
\text { LabVIEW } \\
\text { application } \\
\text { software is used }\end{array}$ & $\begin{array}{l}\text { The system } \\
\text { works only on } \\
\text { single person's } \\
\text { data. } \\
\text { The system } \\
\text { does not } \\
\text { provide any } \\
\text { security } \\
\text { features. }\end{array}$ & $\begin{array}{l}\text { International } \\
\text { conference } \\
\text { on Signal } \\
\text { Processing, } \\
\text { Communi } \\
\text { cation, } \\
\text { Power and } \\
\text { Embedded } \\
\text { System } \\
\text { (SCOPES)- } \\
2016\end{array}$ \\
\hline
\end{tabular}

Fig. 1. Existing Systems

\section{PROPOSED WORK}

Our aim is to develop a smart health monitoring system to monitor the health parameters of the patient securely. A doctor or health specialist can use the system to watch remotely all important health parameters of the patient. This can also be viewed by the patient's family members. Giving care and health assistance to the bedridden patients at critical stages with advanced medical facilities have become one of 
the major problems in the recent times. In hospitals where many patients whose physical conditions must be monitored frequently as a part of a diagnostic procedure, the necessity for a cost-effective and quick responding alert mechanism has become tough. Proper implementation of such systems can provide timely warnings to the medical doctors and their service can be activated in case of medical emergencies.

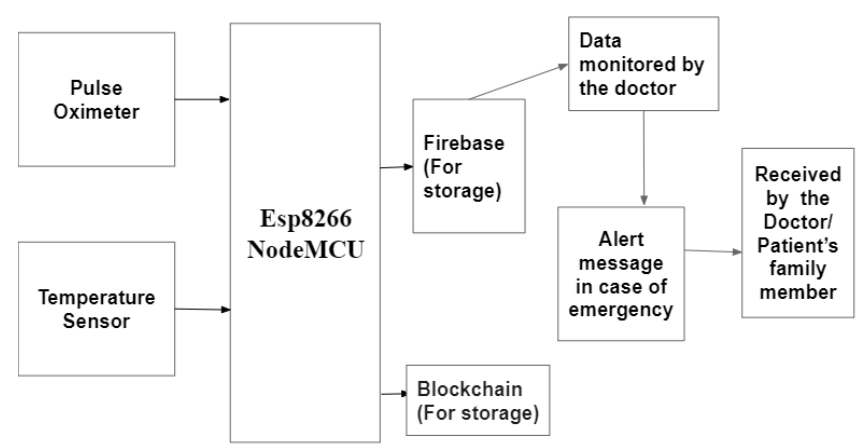

Fig. 2. Sensors are connected to the patient and health parameters are analyzed by the doctor

\section{MATERIALS}

This section discusses the various hardware components included in the project:

1. LM35: LM35 is a temperature sensor used to check the body temperature of the patient. The output values of the sensor are Celsius and Fahrenheit.

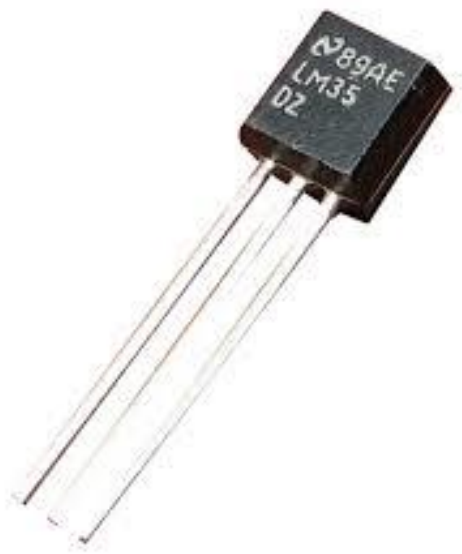

Fig. 3. LM35 (temperature sensor)

2. MAX30100: MAX30100 is a pulse oximeter used to check the oxygen level and heartbeat of the patient.

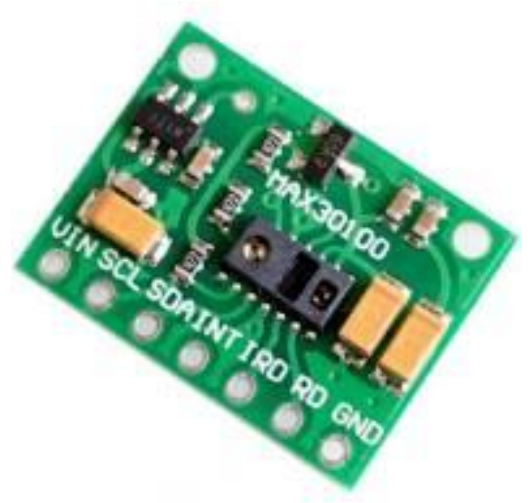

Fig. 4. MAX30100 (pulse oximeter)

3. ESP8266 NodeMCU: It's an open source Iot platform. It is compact and gives an integrated support for Wifi network. It is used to collect the sensor data and send it to the server.

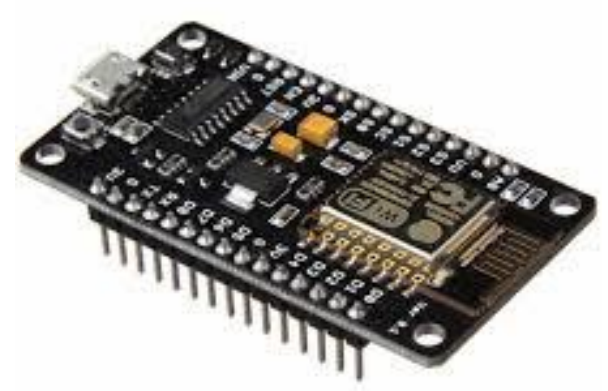

Fig. 5. ESP8266 NodeMCU

\section{RESULTS}

Parameter readings obtained after testing the sensors:

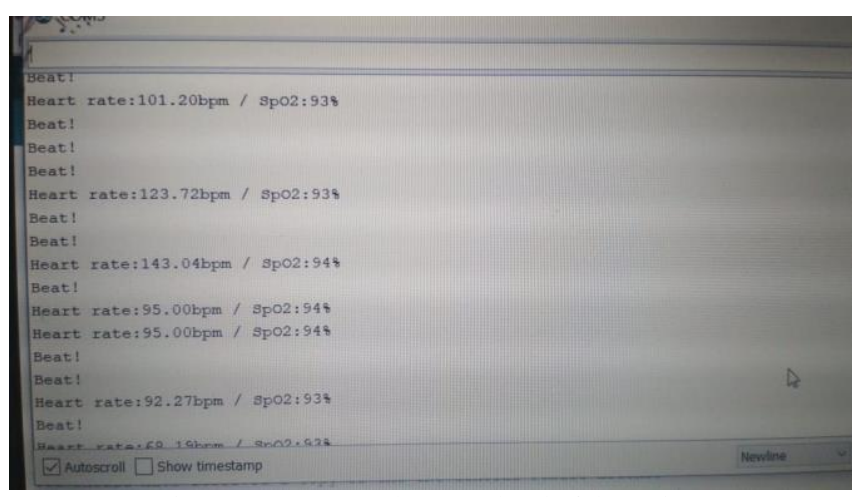

Fig. 6. Heart rate and oxygen level of the patient Real time data of heart rate and oxygen level are using the MAX30100 sensor 


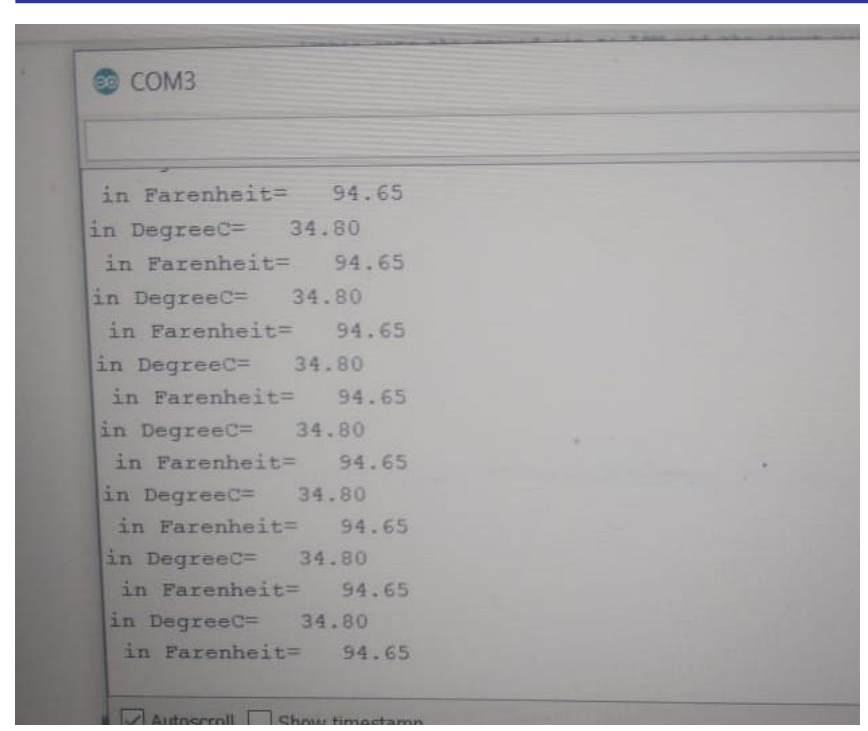

Fig. 7. Temperature value of the patient Real time data of temperature using the LM35 sensor

\section{CONCLUSION}

There are high risks of security issues related to the connected devices. These connected devices are always different from various factors. Centralized architecture have risk such as cost and single point of failure. Thus blockchain provides a solution to these security issues with the decentralized method. Blockchain provides security features to many IoT devices to secure the sensors data transmissions. By providing a decentralized method for a particular doctorpatient entity of a hospital, the data can only be accessed by those doctors of that hospital who are connected with a particular patient. Thus it prevents from hackers who tries to hack the personal data of the patients. In this project we monitor the health parameters such as heart beats, temperature, pulse and oxygen level of the patient. The patient and doctor can view the monitoring updates on the web page of the system through their respective login details. If there are any abnormalities in the health parameters, an alert is sent to the respective doctor and accordingly they can take an emergency action.

\section{ACKNOWLEDGMENT}

Success of the project like this involving technical expertise, patience and massive support of guides, is possible when team members work together. We take this opportunity to express our gratitude to our professors for their tremendous support and help.

\section{REFERENCES}

[1] Salman Ahmed, Sabrin Millat, MD. Aymanur Rahman, Sayeda Naeyna Alam, Md. Saniat Rahman Zishan, 2015 IEEE International WIE Conference on Electrical and Computer Engineering

[2] Vemuri Richard Ranjan Samson, U Bharath Sai, P L S D Malleswara Rao, K Kedar Eswar@ @otti Sriramulu Chalavadi Mallikarjunarao College of Engineering and Technology, Vijayawada, India. ( A paper written under the guidance of Prof. S Pradeep Kumar )

[3] Vikas Vippalapalli and Snigdha Ananthula, ETM Dept.,GNITS, Hyderabad, India, International conference on Signal Processing, Communication, Power and Embedded System (SCOPES)-2016

[4] Roshan Jayswal, Rahul Gupta, K. K. Gup, 2017 Fourth International Conference on Image Information Processing (ICIIP)

[5] https://en.wikipedia.org/wiki/Medical_thermometer\#Basal_thermom eter

[6] https://www.medicalnewstoday.com/articles/318489.php

[7] https://en.wikipedia.org/wiki/Heart_rate_monitor

[8] https://www.fitbit.com/in/inspire 